\title{
Produção e acúmulo de nutrientes em povoamento de eucalipto em consequência da intensidade do desbaste e da fertilização
}

\author{
Jadir Vieira da Silva(1), Gilciano Saraiva Nogueira( ${ }^{(1)}$, Reynaldo Campos Santana ${ }^{(1)}$, Helio Garcia Leite ${ }^{(2)}$, \\ Márcio Leles Romarco de Oliveira ${ }^{(1)}$ e Roosevelt de Paula Almado ${ }^{(3)}$
}

\begin{abstract}
(1)Universidade Federal dos Vales do Jequitinhonha e Mucuri, Campus JK, Programa de Pós Graduação em Ciência Florestal, Rodovia MG 367, no 5.000, Alto do Jacuba, CEP 39100-000 Diamantina, MG. E-mail: jadirvsilva@yahoo.com.br, nogueirags@yahoo.com.br, silviculturaufvjm@yahoo.com.br, marcioromarco@gmail.com (2)Universidade Federal de Viçosa, Departamento de Engenharia Florestal, CEP 36570-000 Viçosa, MG. E-mail: hgleite@gmail.com ${ }^{(3)}$ Avenida Carandaí, no 1.115, 10o andar, Funcionários, CEP $30130-915$ Belo Horizonte, MG. E-mail: roosevelt.almado@arcelormittal.com.br.
\end{abstract}

Resumo - O objetivo deste trabalho foi estimar a produção de madeira e biomassa, bem como a quantidade de nutrientes acumulada, em povoamento de eucalipto submetido a intensidades de desbaste e à fertilização pós-desbaste. O experimento foi realizado em blocos ao acaso, em parcelas subdividas, com duas repetições dos tratamentos dentro de cada bloco. Nas parcelas, foram avaliadas quatro intensidades de desbaste $(0,20$, 35 e $50 \%$ ) e, nas subparcelas, as condições com e sem fertilização pós-desbaste. O desbaste foi realizado aos 89 meses e a aplicação da fertilização aos 99 meses. Os dados foram coletados aos 125 meses. O desbaste influenciou o crescimento em diâmetro, área basal, volume de madeira e biomassa. A fertilização pós-desbaste não afetou o acúmulo de nutrientes pelo povoamento nem sua produção. $\mathrm{O}$ acúmulo de nutrientes na parte aérea e no tronco foi inversamente proporcional à intensidade dos desbastes. O conteúdo de Ca na serapilheira variou de acordo com os desbastes, e o de $\mathrm{K}, \mathrm{Ca}, \mathrm{Mg}$ e $\mathrm{S}$ de acordo com a fertilização. O desbaste tem maior influência do que a fertilização na produção florestal pós-desbaste.

Termos para indexação: Eucalyptus, adubação, balanço nutricional, madeira de desdobro, nutrição mineral.

\section{Production and nutrient accumulation in a eucalyptus plantation as a consequence of thinning intensities and fertilization}

\begin{abstract}
The objective of this work was to estimate the production of wood and biomass, as well as nutrient accumulation, in a eucalyptus plantation subjected to thinning intensities and post-thinning fertilization. The experiment was carried out in randomized blocks, in a split-plot arrangement, with two replicates of treatments within each block. Thinning intensities $(0,20,35$, and 50\%) were evaluated in the plots, and the fertilized and non-fertilized conditions in the split plots. Thinning was done at 89 months, and the fertilizer application at 99 months. Data were collected at 125 months. Thinning affected the diameter growth, basal area, wood volume, and biomass. Post-thinning fertilization did not affect nutrient accumulation by the forest, neither its production. Nutrient accumulation above ground and in the trunks was inversely proportional to thinning intensity. Calcium content in the litter varied with thinning, and the ones of $\mathrm{K}, \mathrm{Ca}, \mathrm{Mg}$, and $\mathrm{S}$, with fertilization. Thinning has a higher influence on forest post-thinning production than fertilization.
\end{abstract}

Index terms: Eucalyptus, fertilization, nutritional balance, sawmill wood, mineral nutrition.

\section{Introdução}

O efeito do desbaste na produção e qualidade de povoamentos florestais tem sido amplamente estudado. As principais publicações têm envolvido a modelagem do crescimento e da produção, antes e após os desbastes. Em geral, buscam-se respostas quanto a intensidades e épocas mais adequadas para o desbaste e quanto a seus efeitos sobre crescimento e qualidade dos povoamentos (Leite et al., 2004; Dias, 2005).
O desbaste provoca substancial incremento em diâmetro, mas não afeta a altura, a não ser em condição de extrema densidade (Kanninen et al., 2004). Os diâmetros máximo e médio são mais afetados do que o mínimo (Gorgens et al., 2007). Campos \& Leite (2009) mencionam que os desbastes não afetam significativamente a produção bruta dos povoamentos. Segundo os autores, a decisão sobre a prática do desbaste deve ser baseada em considerações econômicas e levar em conta a possibilidade da produção de árvores com maior valor individual. 
No entanto, a fertilização em áreas desbastadas tem mostrado efeito altamente significativo sobre o crescimento em diâmetro, altura e volume (Harrington $\&$ Devine, 2011). A prática do desbaste tende a reverter o estágio de desenvolvimento do povoamento para o estágio anterior ao de fechamento de copas, o que torna bastante provável a resposta à fertilização (Chaves et al., 2007). O sistema mais indicado para a recomendação de fertilizantes, em florestas de eucalipto, baseia-se no balanço nutricional estabelecido entre a demanda de nutrientes pela cultura, para uma determinada produtividade, e o suprimento pelo solo, serapilheira e outras fontes naturais (Barros et al., 1995).

Segundo Wollum \& Schubert (1975), as condições de mineralização da serapilheira, em um povoamento florestal, são influenciadas pela intensidade de desbaste. Após o desbaste, ocorre mudança no microclima da floresta, com aumento da radiação solar incidente nas árvores remanescentes e redução da evapotranspiração. O desbaste pode diminuir a competição entre as raízes das árvores e microrganismos por água e nutrientes, e melhorar a mineralização da matéria orgânica. $\mathrm{O}$ desbaste promove a abertura do dossel e o desenvolvimento de ramos epicórnicos, o que resulta na expansão da copa e na retomada do crescimento das árvores. A expansão da copa, por esta ser a parte da planta mais rica em nutrientes (Silva, 1999), aumenta a demanda nutricional, o que pode causar deficiências.

No entanto, são escassos os estudos que analisam simultaneamente o efeito da fertilização e do desbaste em floresta de eucalipto, mesmo com o grande interesse existente quanto à produção de árvores de grande diâmetro, próprias para usos mais nobres da madeira. Em outras espécies, o efeito do desbaste e da fertilização na produção florestal é conhecido (Haywood, 2005; Harrington \& Devine, 2011).

O objetivo deste trabalho foi estimar a produção de madeira e biomassa, bem como a quantidade de nutrientes acumulada, em povoamento de eucalipto submetido a intensidades de desbaste e à fertilização pós-desbaste.

\section{Material e Métodos}

O experimento foi instalado em povoamento de clones de eucalipto, em propriedade da empresa ArcellorMittal BioFlorestas, em Martinho Campos, MG. O clima da região é do tipo $\mathrm{Cwa}$, segundo a classificação de Köppen, caracterizado por verões úmidos e invernos secos, com temperatura média anual entre 19,8 e $25,3^{\circ} \mathrm{C}$, e precipitação média anual de $1.400 \mathrm{~mm}$.

O experimento foi realizado em blocos ao acaso, em arranjo de parcelas subdivididas, com dois blocos e duas repetições por bloco. Os blocos com tratamentos repetidos permitiram obter um maior número de graus de liberdade para o resíduo. Os blocos foram instalados em dois locais com capacidade produtivas diferentes: bloco 1, com índice de sítio de $21 \mathrm{~m}$, e bloco 2, comíndice de sítio de $17 \mathrm{~m}$. Foram avaliadas quatro intensidades de desbaste e dois níveis de fertilização, aplicados em parcelas gêmeas (Stape et al., 2006), o que totalizou, em campo, 30 parcelas de inventário florestal contínuo, das quais 16 sem aplicação da fertilização e 14 gêmeas (com aplicação da fertilização). As parcelas gêmeas foram instaladas ao lado das parcelas sem aplicação da fertilização e, por motivos operacionais, duas delas não foram instaladas. Assim, em cada bloco, a parcela gêmea de uma das repetições da testemunha (sem desbaste e sem fertilização) não foi instalada, o que resultou em sete parcelas gêmeas por bloco. Na análise estatística do experimento, estas parcelas foram consideradas como perdidas, e as médias dos valores obtidos nas outras repetições da testemunha (média de duas parcelas em cada bloco) foram consideradas como estimativas das parcelas perdidas. $\mathrm{O}$ efeito principal e o da interação dos fatores desbaste (parcela) e fertilização (subparcela) foram avaliados sobre a produção de biomassa e o acúmulo de nutrientes em diferentes componentes das árvores.

Os níveis de fertilização utilizados foram: F0, sem fertilizantes, e F1, com fertilizantes. Os procedimentos de campo para fertilização e a quantidade e tipo de fertilizantes (quilogramas de macronutrientes por hectare) foram definidos com base no sistema de balanço nutricional (Barros et al., 1995). Para isto, foram colhidas 15 árvores-amostra, e a árvore com o valor do diâmetro quadrático médio da parcela, em que cada parcela representava um tratamento de desbaste $(0,20,35$ e $50 \%$ de remoção de área basal).

Na definição da fertilização pelo sistema de balanço nutricional, se a diferença entre exportação e suprimento de nutrientes for positiva, realiza-se a aplicação de fertilizante; quando negativa ou nula, não se realiza a aplicação de fertilizante. Considerou-se que 100\% dos nutrientes contidos nas folhas e galhos das árvores 
removidas foram novamente absorvidos pelas plantas remanescentes, à medida que forem mineralizados. Cada nutriente, uma vez obtida a quantidade acumulada na árvore ou em parte dela, foi dividido por sua taxa de recuperação no solo, para obter o requerimento da planta pelo nutriente.

Como na análise química de solo o teor de um nutriente indicado é apenas um índice de disponibilidade e não o teor realmente disponível, dividiu-se o teor de um nutriente indicado na análise de solo pela respectiva taxa de recuperação do extrator, para obter a quantidade do nutriente suprida pelo solo $\left(\mathrm{mg} \mathrm{dm}{ }^{-3}\right)$. Em seguida, multiplicou-se o valor obtido, pelo volume de solo contido até $40 \mathrm{~cm}$ de profundidade $\left(\mathrm{dm}^{3} \mathrm{ha}^{-1}\right)$ e, depois, dividiu-se o resultado por um milhão (para transformar $\mathrm{mg} \mathrm{ha}^{-1} \mathrm{em} \mathrm{kg} \mathrm{ha-1}^{-1}$ ). Obtevese, assim, o suprimento de nutriente pelo solo $\left(\mathrm{kg} \mathrm{ha}^{-1}\right)$. Neste trabalho, considerou-se que $100 \%$ dos nutrientes disponíveis na camada de 0 a 20 , e $50 \%$ na camada de $20 \mathrm{a} 40 \mathrm{~cm}$, foram absorvidos pela planta.

O desbaste foi realizado aos 89 meses, em fevereiro de 2008. A idade ao desbaste foi determinada pelo método dos ingressos percentuais (Nogueira et al., 2001). A aplicação da fertilização foi realizada 10 meses após o desbaste, ou seja, aos 99 meses, em dezembro de 2008. A fertilização realizada para cada tratamento de desbaste está apresentada na Tabela 1.

Após definida a fertilização a ser aplicada, foram implementados os seguintes tratamentos com desbaste: T1, testemunha (sem desbaste e sem fertilização); T2, $20 \%$ de desbaste seletivo na área basal presente, com eliminação dos piores indivíduos; T3, 35\% de desbaste seletivo na área basal presente, com eliminação dos piores indivíduos; T4, 50\% de desbaste seletivo na área basal presente, com eliminação dos piores indivíduos. Os tratamentos com desbaste foram dispostos em arranjo fatorial com os tratamentos de fertilização (com ou sem fertilização pós-desbaste).

Tabela 1. Fertilização aplicada às parcelas gêmeas, de acordo com as intensidades de desbaste.

\begin{tabular}{|c|c|c|}
\hline Desbaste & NPK 06-30-12(1) & $\mathrm{KCl}^{(2)}$ \\
\hline$(\%)$ & ----------------( & --------------- \\
\hline 0 & 0 & 0 \\
\hline 20 & 55 & 0 \\
\hline 35 & 111 & 78 \\
\hline 50 & 202 & 267 \\
\hline
\end{tabular}

O efeito dos tratamentos foi avaliado com os dados obtidos aos 124,9 meses. As variáveis analisadas, resultantes da totalização dos dados das parcelas, foram: volume total com casca (Vcc), volume individual médio com casca (Vicc), área basal (B), diâmetro quadrático médio (q), altura total média $\left(\mathrm{H}_{\mathrm{t}}\right)$, altura dominante $\left(\mathrm{H}_{\mathrm{d}}\right)$ e altura da copa $\left(\mathrm{h}_{\text {copa }}\right)$. Material vegetal foi coletado para obtenção das seguintes variáveis: biomassa total e quantidade de nutrientes na parte aérea e na serapilheira. Foram considerados: tronco (casca e lenho) e a parte aérea total (casca, lenho, folha e galho).

O cálculo de volume, biomassa e conteúdo de nutrientes foi realizado conforme a metodologia da árvore-modelo (Campos \& Leite, 2009), ou seja, com seleção de uma árvore, com valor referente ao diâmetro quadrático médio da parcela, para representá-la (repetição do tratamento). Em cada árvore-modelo, foram realizadas a cubagem rigorosa e a análise de macro nutrientes dos componentes: folha, galho, casca e tronco.

Após a realização da cubagem rigorosa pelo método de Smalian (Campos \& Leite, 2009), cada árvore foi dividida em lenho, casca, ramos e folhas, e seus componentes foram pesados. As amostras de galhos e folhas foram coletadas após homogeneização do material; para a análise de lenho, foram coletadas amostras de serragem. A casca foi amostrada em toda a extensão do tronco. Estas subamostras foram submetidas à secagem a $65^{\circ} \mathrm{C}$, em estufa com circulação forçada de ar, até massa constante, para determinação da matéria seca.

As amostras de serapilheira acumuladas sobre o solo foram coletadas nas extremidades e no centro da parcela, em cinco pontos para cada tratamento, em área de $0,25 \mathrm{~m}^{2}$, delimitada por gabarito de $50 \times 50 \mathrm{~cm}$. As amostras da serapilheira foram homogeneizadas após obtenção de seu peso total, para obtenção de uma subamostra composta para a análise química dos macronutrientes.

As amostras de solo foram coletadas de três profundidades, no centro da parcela: 0-20, 20-40 e 40-60. A partir das amostras simples, nas parcelas, foram determinadas amostras compostas, de forma que cada tratamento fosse representado por uma amostra composta de cada profundidade. Foram determinados: pH em água; $\mathrm{P}$ e $\mathrm{K}$, extraídos em $\mathrm{Mehlich}^{-1} ; \mathrm{Ca}^{+2}$, $\mathrm{Mg}^{+2}$ e $\mathrm{Al}^{+3}$, extraídos com $\mathrm{KCl} 1 \mathrm{~mol} \mathrm{~L}^{-1} ; \mathrm{H}+\mathrm{Al}$, determinado por extração com $\mathrm{Ca}(\mathrm{OAc})_{2}$ a $0,5 \mathrm{~mol} \mathrm{~L}^{-1}$ 
(pH 7,0); e carbono orgânico (CO), obtido pelo método de Walkley-Black. Realizou-se apenas uma análise física do solo por tratamento.

Nas amostras de tecido vegetal e serapilheira, determinaram-se os teores de: $\mathrm{P}$, por calorimetria; $\mathrm{K}$, por fotometria de emissão de chama; $\mathrm{Ca}$ e $\mathrm{Mg}$, por espectrofotometria de absorção atômica; $\mathrm{N}$ total, pelo método Kjeldahl. O conteúdo de cada nutriente foi estimado pela multiplicação de seu teor pela massa de matéria seca do componente em questão. A eficiência de utilização dos nutrientes foi determinada por meio da relação entre massa de matéria seca e quantidade acumulada de nutrientes na matéria seca de cada componente.

Estimou-se, também, a intensidade luminosa (radiação fotossinteticamente ativa, PAR), determinada com o aparelho Accupar na altura aproximada de $1 \mathrm{~m}$ do solo, em cinco pontos, nas extremidades e no centro da parcela.

Para verificar a normalidade dos dados, empregouse o teste de Lilliefors e, para a homogeneidade de variância, empregaram-se os testes de Cochran e de Bartley. Empregou-se o teste de Tukey, a 5\% de probabilidade, para comparações múltiplas entre médias. As análises estatísticas foram realizadas com auxílio do programa Statistica 10.0.

\section{Resultados e Discussão}

Não houve interação significativa entre desbastes e fertilização em nenhuma das características avaliadas. $O$ efeito principal da fertilização também não foi não significativo para nenhuma variável analisada; o desbaste, no entanto, teve efeito significativo sobre o volume de madeira por hectare, incremento médio anual, biomassa por hectare, diâmetro quadrático médio e área basal. Nenhum tratamento produziu efeito sobre volume por árvore, altura total, altura dominante e comprimento de copa.

Segundo Miller (1995), após o fechamento das copas, a demanda nutricional do povoamento passa a ser suprida predominantemente pela ciclagem de nutrientes. Isto pode explicar a ausência de influência da fertilização pós-desbaste nas variáveis analisadas, já que a fertilização pós-desbaste foi feita em idade avançada da floresta, quando a ciclagem de nutrientes predominava.
A ausência de efeito do desbaste sobre altura total e dominante comprova que essas variáveis não são afetadas quando o povoamento se encontra em idade avançada (Sanquetta et al., 2004; Trevisan et al., 2007; Monte et al., 2009). Esse resultado, aliado à baixa magnitude do efeito do desbaste sobre o diâmetro (Tabela 2), fez com que também não se observasse diferença significativa sobre o volume individual por árvore.

Nenhum dos efeitos principais foi significativo para as variáveis de potencial mátrico do solo, intensidade luminosa e quantidade de serapilheira por hectare. O método de desbaste seletivo, possivelmente, explica esse resultado, pois não houve uniformidade espacial entre plantas. Em relação a outros trabalhos (Kolm \& Poggiani, 2003; Freitas et al., 2004; Cunha et al., 2005), observou-se alta quantidade de serapilheira acumulada sobre o solo.

A ausência de efeito significativo do desbaste na intensidade luminosa e na produção de serapilheira se atribui, principalmente, ao fato de que: não houve diferença na altura de desrama, altura total e altura dominante; e ao fato de o desbaste não ter sido seletivo, tendo-se eliminado apenas os piores indivíduos, o que fez com que o dossel superior das parcelas se mantivesse inalterado, mesmo no tratamento com 50\% de desbaste.

Os tratamentos de desbaste, no entanto, apresentaram diferenças significativas quanto à área basal e ao número de árvores. Para as variáveis volume total com casca, incremento médio anual e produção de biomassa, as maiores produções ocorreram nos tratamentos com maior número de árvores remanescentes (Tabela 2). Esses resultados estão de acordo com Medhurst et al. (2001), Trevisan et al. (2007) e Monte et al. (2009), em

Tabela 2. Volume com casca (Vcc), incremento médio anual (IMA), biomassa total (W), área basal (g) e diâmetro médio (dq) de povoamento de eucalipto aos 124,9 meses, após ter sido submetido a intensidades $(0,20,35$ e $50 \%)$ de desbaste aos 89 meses $^{(1)}$.

\begin{tabular}{lccccc}
\hline $\begin{array}{l}\text { Desbaste } \\
(\%)\end{array}$ & $\begin{array}{c}\text { Vcc } \\
\left(\mathrm{m}^{3} \mathrm{ha}^{-1}\right)\end{array}$ & $\begin{array}{c}\text { IMA } \\
\left(\mathrm{m}^{3} \mathrm{ha}^{-1} \text { por ano }\right)\end{array}$ & $\begin{array}{c}\mathrm{W} \\
\left(\mathrm{Mg} \mathrm{ha}^{-1}\right)\end{array}$ & $\begin{array}{c}\mathrm{g} \\
\left(\mathrm{m}^{2} \mathrm{ha}^{-1}\right)\end{array}$ & $\begin{array}{c}\mathrm{dq} \\
(\mathrm{cm})\end{array}$ \\
\hline 0 & $373,2 \mathrm{a}$ & $35,9 \mathrm{a}$ & $206,1 \mathrm{a}$ & $26,0 \mathrm{a}$ & $14,7 \mathrm{c}$ \\
20 & $337,8 \mathrm{ab}$ & $32,5 \mathrm{ab}$ & $187,8 \mathrm{ab}$ & $23,1 \mathrm{~b}$ & $15,9 \mathrm{~b}$ \\
35 & $269,7 \mathrm{bc}$ & $25,9 \mathrm{bc}$ & $145,4 \mathrm{bc}$ & $18,8 \mathrm{c}$ & $16,5 \mathrm{ab}$ \\
50 & $207,6 \mathrm{c}$ & $19,9 \mathrm{c}$ & $112,4 \mathrm{c}$ & $14,8 \mathrm{~d}$ & $16,8 \mathrm{a}$ \\
\hline
\end{tabular}

${ }^{(1)}$ Médias seguidas de letras iguais não diferem, entre si, pelo teste de Tukey, a $5 \%$ de probabilidade. 
que menores intensidades de desbaste resultaram em maior produção do povoamento florestal. Os desbastes mais intensos proporcionaram maiores incrementos em diâmetro. A diminuição no número de árvores reduz a competição, o que favorece a retomada no crescimento em diâmetro. Resultados semelhantes também foram observados por Kanninen et al. (2004), Dias (2005) e Monte et al. (2009).

A quantidade acumulada de nutrientes no tronco diminuiu com a intensificação do desbaste (Tabela 3). Este resultado era esperado, uma vez que a biomassa de tronco por hectare é fortemente afetada pelo desbaste. Santana et al. (2002) também observaram correlação positiva direta entre produção de biomassa e acúmulo de nutrientes.

Tabela 3. Quantidade de macronutrientes acumulada no tronco (casca e lenho), na parte aérea (folha,galho, casca e lenho) e na serapilheira de povoamento de eucalipto com 124,9 meses, submetido a intensidades $(0,20,35$ e $50 \%$ ) de desbaste aos 89 meses, sem e com fertilização pós-desbaste aos 99 meses.

\begin{tabular}{|c|c|c|c|c|c|c|c|}
\hline \multirow[t]{2}{*}{ Tratamento } & \multirow{2}{*}{$\begin{array}{l}\text { Biomassa } \\
\left(\mathrm{Mg} \mathrm{ha}^{-1}\right)\end{array}$} & $\mathrm{N}$ & $P$ & K & $\mathrm{Ca}$ & $\mathrm{Mg}$ & $\mathrm{S}$ \\
\hline & & \multicolumn{6}{|c|}{ - } \\
\hline & \multicolumn{7}{|c|}{ Tronco } \\
\hline 0 Sem fertilização & 193,9 & 222,4 & 27,9 & 372,7 & 286,1 & 39,7 & 49,1 \\
\hline 0 Com fertilização & 192,3 & 229,7 & 35,4 & 316,2 & 283,4 & 39,9 & 52,6 \\
\hline 20 Sem fertilização & 172,6 & 224,8 & 29,3 & 363,8 & 213,8 & 34,5 & 55,6 \\
\hline 20 Com f & 6 & 223,0 & 33,8 & 274,8 & 303,6 & 47,9 & 54,4 \\
\hline $35 \mathrm{Sem} \mathrm{fe}$ & 124,5 & 154,6 & 20,4 & 200,3 & 195,6 & 21,5 & 34,4 \\
\hline 35 Cor & ,0 & 157,2 & 25,0 & 234,5 & 216,0 & 34,5 & 38,6 \\
\hline ilização & 101,3 & 128,6 & 24,5 & 206,1 & 176,4 & 25,6 & 29,1 \\
\hline \multirow[t]{2}{*}{50 Com fertilização } & & 125,9 & 18,6 & 180,3 & 157,4 & 21,9 & 29,6 \\
\hline & \multicolumn{7}{|c|}{ Parte aérea total } \\
\hline $0 \mathrm{Sem}$ & 207,1 & 372,4 & 43,9 & 436,1 & 354,8 & 56,4 & 60,9 \\
\hline 0 Com & 205,1 & 382,8 & 50,0 & 381,5 & 365,5 & 59,6 & 65,4 \\
\hline ização & 184,5 & 357,1 & 42,2 & 424,3 & 275,9 & 48,7 & 65,9 \\
\hline 20 Com fertilização & 191,1 & 377,1 & 45,6 & 346,9 & 393,2 & 68,3 & 67,2 \\
\hline ização & 136,9 & 288,4 & 31,0 & 270,5 & 267,6 & 36,8 & 45,5 \\
\hline 35 Com fertilização & 154,0 & 294,1 & 36,3 & 303,9 & 298,6 & 54,4 & 50,3 \\
\hline zação & 112,8 & 253,9 & 35,1 & 266,7 & 241,7 & 40,2 & 39,4 \\
\hline \multirow[t]{2}{*}{50 Com fertilização } & 111,9 & 236,9 & 28,5 & 244,1 & 218,4 & 35,5 & 38,9 \\
\hline & \multicolumn{7}{|c|}{ Serapilheira } \\
\hline $0 \mathrm{Se}$ & & 112,6 & 6,5 & 7,7 & 118,4 & 16,9 & 16,1 \\
\hline 0 Com fertilização & 17,0 & 104,6 & 6,7 & 7,9 & 121,6 & 16,0 & 21,4 \\
\hline 20 Sem fertilização & 16,5 & 98,2 & 5,4 & 9,5 & 97,6 & 16,4 & 13,1 \\
\hline 20 Com fertilização & 15,6 & 99,9 & 6,3 & 8,8 & 112,6 & 17,3 & 18,4 \\
\hline 35 Sem fertilização & 16,0 & 90,4 & 5,4 & 7,7 & 86,8 & 13,5 & 15,2 \\
\hline 35 Com fertilização & 16,0 & 108,2 & 6,9 & 9,0 & 116,9 & 17,3 & 18,2 \\
\hline 50 Sem fertilização & 15,5 & 109,9 & 6,4 & 7,7 & 105,8 & 15,3 & 15,3 \\
\hline 50 Com fertilização & 18,0 & 107,7 & 7,2 & 8,8 & 123,8 & 17,5 & 20,5 \\
\hline
\end{tabular}

A quantidade de nutrientes acumulada no tronco e na parte aérea total seguiu a ordem $\mathrm{K}>\mathrm{Ca}>\mathrm{N}>\mathrm{S}>\mathrm{Mg}>\mathrm{P}$ (Tabela 3). Essa ordem difere da observada em estudos com povoamentos de eucalipto não desbastados, em que, de modo geral, a quantidade total de $\mathrm{N}$ é maior do que a de K (Andrade et al., 2006; Faria et al., 2008). No entanto, esse resultado está de acordo com os de Santana et al. (2008), que observaram maiores valores de $\mathrm{K}$ em povoamentos com idades superiores a oito anos de idade. Com o aumento da idade, os autores relataram que há tendência de redução dos nutrientes alocados na copa e de aumento dos nutrientes alocados no tronco.

A eficiência de utilização (EUN) indica a quantidade de matéria seca produzida com um quilo de nutriente. Em média, a EUN não foi alterada pelo desbaste e nem pela fertilização (Tabela 4), com exceção do $\mathrm{Ca}$, que apresentou menor eficiência com o uso da fertilização na intensidade de desbaste de 20\% (Tabela 5). Esse nutriente apresentou resposta significativa à fertilização na intensidade de $20 \%$ de desbaste, tanto na quantidade acumulada no tronco como na parte aérea total. Quanto à intensidade de desbaste, menores intensidades acumularam maiores quantidades do nutriente cálcio.

Tabela 4. Eficiência de utilização nutricional de macronutrientes ( $\mathrm{kg}$ de biomassa por $\mathrm{kg}$ de nutriente), no tronco (casca e lenho) e parte aérea (folha, galho, casca e lenho) de povoamento de eucalipto aos 124,9 meses, submetido a intensidades $(0,20,35$ e $50 \%)$ de desbaste aos 89 meses, sem e com fertilização pós-desbaste aos 99 meses.

\begin{tabular}{lcccccc}
\hline Tratamento & $\mathrm{N}$ & $\mathrm{P}$ & $\mathrm{K}$ & $\mathrm{Ca}$ & $\mathrm{Mg}$ & $\mathrm{S}$ \\
\hline 0 Sem fertilização & 872 & 6949 & 520 & 678 & 4883 & 3949 \\
0 Com fertilização & 844 & 5477 & 613 & 684 & 4859 & 3686 \\
20 Sem fertilização & 862 & 6617 & 533 & 907 & 5620 & 3487 \\
20 Com fertilização & 869 & 5736 & 706 & 639 & 4047 & 3564 \\
35 Sem fertilização & 1254 & 9504 & 968 & 991 & 9017 & 5636 \\
35 Com fertilização & 1233 & 7755 & 827 & 898 & 5620 & 5023 \\
50 Sem fertilização & 1508 & 7913 & 941 & 1099 & 7573 & 6662 \\
50 Com fertilização & 1540 & 10423 & 1075 & 1232 & 8853 & 6550 \\
\hline & & \multicolumn{5}{c}{ Parte aérea } \\
0 Sem fertilização & 521 & 4416 & 445 & 546 & 3437 & 3183 \\
0 Com fertilização & 506 & 3877 & 508 & 530 & 3253 & 2964 \\
20 Sem fertilização & 543 & 4594 & 457 & 703 & 3981 & 2942 \\
20 Com fertilização & 514 & 4252 & 559 & 493 & 2839 & 2885 \\
35 Sem fertilização & 672 & 6254 & 717 & 724 & 5268 & 4261 \\
35 Com fertilização & 659 & 5341 & 638 & 649 & 3564 & 3854 \\
50 Sem fertilização & 764 & 5523 & 727 & 802 & 4823 & 4921 \\
50 Com fertilização & 818 & 6803 & 794 & 888 & 5461 & 4984 \\
\hline
\end{tabular}


Os nutrientes $\mathrm{N}, \mathrm{Mg}$ e $\mathrm{S}$ sofreram efeito significativo apenas do desbaste. A quantidade acumulada de nitrogênio no tronco e total foi maior nas menores intensidades de desbaste (Figura 1). O mesmo fato pôde ser verificado com relação ao enxofre. Estes resultados eram esperados, uma vez que menores espaçamentos acumulam maior quantidade de nutrientes (Müller, 2005).

A ordem de acúmulo de nutrientes na serapilheira foi $\mathrm{N}>\mathrm{Ca}>\mathrm{S}>\mathrm{Mg}>\mathrm{K}>\mathrm{P}$ (Tabela 3). Resultados semelhantes foram constatados por Gama-Rodrigues \& Barros (2002), Freitas et al. (2004), Cunha et al. (2005). A baixa quantidade de $\mathrm{K}$ acumulada na serapilheira pode estar relacionada à mobilidade deste nutriente, que é facilmente lixiviado das folhas. A quantidade de nutrientes acumulada na serapilheira depende da espécie, da proporção de folhas em relação aos demais componentes das árvores e da capacidade de translocação dos nutrientes antes da senescência (Schumacher \& Poggiani, 1993).

O nível de $20 \%$ de desbaste promoveu o maior ganho de matéria seca total após o desbaste, com $35 \mathrm{Mg} \mathrm{ha}^{-1}$ (Tabela 2). Ao dividir a produção de matéria seca pelos valores de EUN (Tabela 5), foram obtidas as quantidades de nutrientes acumuladas para as produções observadas pós-desbaste: $68 \mathrm{~kg} \mathrm{ha}^{-1} \mathrm{~N}$, $8 \mathrm{~kg} \mathrm{ha}^{-1} \mathrm{P}, 71 \mathrm{~kg} \mathrm{ha}^{-1} \mathrm{~K}, 61 \mathrm{~kg} \mathrm{ha}^{-1} \mathrm{Ca}, 11 \mathrm{~kg} \mathrm{ha}^{-1} \mathrm{Mg}$ e $12 \mathrm{~kg} \mathrm{ha}^{-1} \mathrm{~S}$. De acordo com Brandani (2010), a taxa de decomposição da serapilheira de eucalipto, em diferentes regiões do Brasil, ocorre no tempo médio de 667 dias (em condições semelhantes ao povoamento estudado). Se aplicarmos esse resultado ao acúmulo de nutrientes na serapilheira (Tabela 3), e considerarmos desprezíveis as perdas por lixiviação no solo e uma rápida e eficiente absorção de nutrientes, esta seria capaz de fornecer 99, $1 \mathrm{~kg} \mathrm{ha}^{-1} \mathrm{~N}, 5,9 \mathrm{~kg} \mathrm{ha}^{-1} \mathrm{P}, 9,2 \mathrm{~kg} \mathrm{ha}^{-1} \mathrm{~K}$,
105,1 $\mathrm{kg} \mathrm{ha}^{-1} \mathrm{Ca}, 16,9 \mathrm{~kg} \mathrm{ha}^{-1} \mathrm{Mg}$ e 15,8 $\mathrm{kg} \mathrm{ha}^{-1} \mathrm{~S}$, valores superiores aos demandados para a produção de matéria seca pós-desbaste. Além da serapilheira, o solo é outra fonte de nutrientes a ser computada. Assim, se considerarmos que o eucalipto tem condições de absorver 70, 50 e 30\% dos nutrientes disponíveis do solo, respectivamente, para as profundidades de 0 a 20, 20 a 40 e 40 a $60 \mathrm{~cm}$ para $\mathrm{P}, \mathrm{K}, \mathrm{Ca}$ e $\mathrm{Mg}$, isto possibilitaria absorção de 4,4 $\mathrm{kg} \mathrm{ha}^{-1} \mathrm{P}, 32,5 \mathrm{~kg} \mathrm{ha}^{-1} \mathrm{~K}$, $227,4 \mathrm{~kg} \mathrm{ha}^{-1} \mathrm{Ca}$ e $71,7 \mathrm{~kg} \mathrm{ha}^{-1} \mathrm{Mg}$. Além dessas fontes, ainda existe a possibilidade de entrada de nutrientes provenientes da atmosfera, que não foi considerada. Portanto, estas são as prováveis razões para a ausência de resposta do povoamento à fertilização realizada, para a maioria dos nutrientes avaliados.

Quanto ao conteúdo de nutrientes da serapilheira, a interação dos efeitos principais dos fatores de variação não foi significativa em nenhum dos nutrientes avaliados. As quantidades de $\mathrm{K}, \mathrm{Ca}, \mathrm{Mg}$ e $\mathrm{S}$ na serapilheira aumentaram com a fertilização pós-desbaste. Os tratamentos que receberam a fertilização pós-desbaste resultaram em maior conteúdo de $\mathrm{K}, \mathrm{Ca}, \mathrm{Mg}$ e $\mathrm{S}$ acumulados na serapilheira. Com relação ao desbaste, apenas a quantidade de $\mathrm{Ca}$ na serapilheira foi estatisticamente influenciada (Tabela 5), com os maiores valores obtidos na testemunha e na intensidade de desbaste de $50 \%$. A alta quantidade de $\mathrm{Ca}$ na serapilheira pode ser explicada pela baixa mobilidade do nutriente na planta, pois não há redistribuição para partes novas da planta antes da abscisão foliar.

Kolm \& Poggiani (2003) verificaram a ocorrência de maior quantidade de $\mathrm{K}, \mathrm{Ca}$ e $\mathrm{Mg}$ imobilizados na serapilheira de um povoamento desbastado de Eucalyptus grandis, principalmente nas menores intensidades de desbaste. Estes autores constataram,

Tabela 5. Quantidades de cálcio no tronco, parte aérea e serapilheira $\left(\mathrm{kg} \mathrm{ha}^{-1}\right)$, e eficiência nutricional ( $\mathrm{kg}$ de matéria seca na parte aérea por $\mathrm{kg}$ de $\mathrm{Ca}$ ) de povoamento de eucalipto aos 124,9 meses, submetido a intensidades (0, 20, 35 e 50\%) de desbaste aos 89 meses, sem e com fertilização (fertil.) pós-desbaste aos 99 meses $^{(1)}$.

\begin{tabular}{|c|c|c|c|c|c|c|c|c|c|c|c|c|}
\hline \multirow{2}{*}{$\begin{array}{l}\text { Desbaste } \\
(\%) \\
\end{array}$} & \multicolumn{2}{|c|}{ Ca no tronco } & \multirow[t]{2}{*}{ Média } & \multicolumn{2}{|c|}{ Ca na parte aérea } & \multirow[t]{2}{*}{ Média } & \multicolumn{2}{|c|}{ Ca na serapilheira } & \multirow[t]{2}{*}{ Média } & \multicolumn{2}{|c|}{ Eficiência nutricional } & \multirow[t]{2}{*}{ Média } \\
\hline & Sem fertil. & Com fertil. & & Sem fertil. & Com fertil. & & Sem fertil. & Com fertil. & & Sem fertil. & Com fertil. & \\
\hline 0 & $286 \mathrm{aA}$ & $283 \mathrm{aA}$ & $360 a$ & $354 \mathrm{aA}$ & $365 \mathrm{aA}$ & $360 \mathrm{a}$ & 118,4 & 123,9 & $119,97 \mathrm{a}$ & $546 \mathrm{aA}$ & $530 \mathrm{aA}$ & $538 \mathrm{c}$ \\
\hline 20 & $213 \mathrm{abA}$ & $303 \mathrm{aB}$ & $334 \mathrm{a}$ & $275 \mathrm{bA}$ & $393 \mathrm{aB}$ & $334 \mathrm{a}$ & 97,6 & 118,6 & $105,13 b$ & $703 \mathrm{aA}$ & $493 \mathrm{aB}$ & $598 \mathrm{c}$ \\
\hline 35 & $195 \mathrm{abA}$ & $216 \mathrm{abA}$ & $283 \mathrm{ab}$ & $267 \mathrm{bA}$ & $298 \mathrm{bA}$ & $283 \mathrm{ab}$ & 86,8 & 116,9 & $101,87 b$ & $724 \mathrm{aA}$ & $649 \mathrm{aA}$ & $687 b$ \\
\hline 50 & $176 \mathrm{bA}$ & $157 \mathrm{bA}$ & $230 \mathrm{~b}$ & $241 \mathrm{bA}$ & $218 \mathrm{bA}$ & $230 \mathrm{~b}$ & 105,8 & 112,6 & $114,81 \mathrm{ab}$ & $802 \mathrm{aA}$ & $888 \mathrm{aA}$ & $845 a$ \\
\hline Média & $217,96 \mathrm{~B}$ & $240,11 \mathrm{~A}$ & & $285,02 \mathrm{~B}$ & $318,92 \mathrm{~A}$ & & $102,14 \mathrm{~B}$ & $117,99 \mathrm{~A}$ & & 658 & 557 & \\
\hline
\end{tabular}

${ }^{(1)}$ Médias seguidas de letras iguais, minúsculas nas colunas e maiúsculas nas linhas, não diferem, entre si, pelo teste de Tukey, a 5\% de probabilidade. 


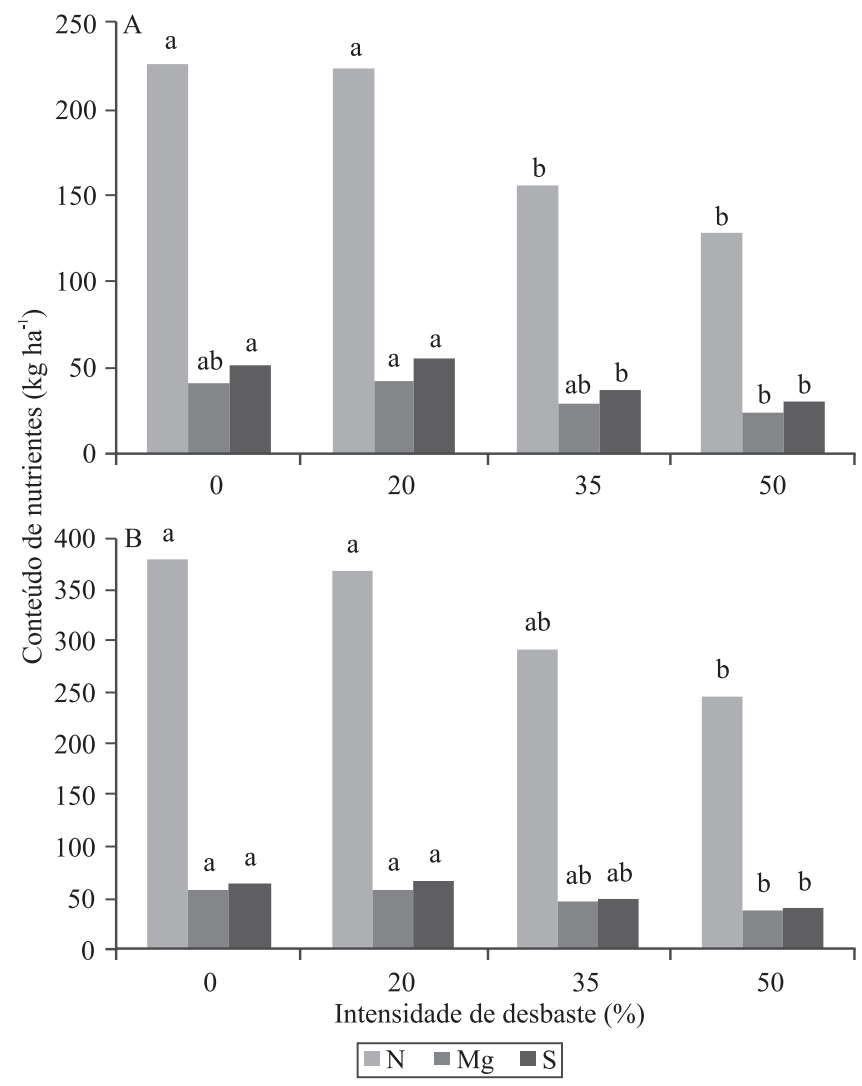

Figura 1. Efeito de intensidades de desbaste sobre a quantidade acumulada de $\mathrm{N}, \mathrm{Mg}$ e $\mathrm{S}$ no tronco (A) e na parte aérea total (B). Médias seguidas de letras iguais não diferem, entre si, pelo teste de Tukey, a 5\% de probabilidade.

ainda, que a transferência de nutrientes ao solo, pela decomposição da serapilheira, é maior nos tratamentos desbastados, ou seja, o desbaste aperfeiçoa a reposição nutricional das árvores via ciclagem de nutrientes, além favorecer a manutenção da fertilidade do solo.

\section{Conclusões}

1. O desbaste realizado aos 89 meses influencia significativamente o diâmetro quadrático médio, a área basal, o volume e a biomassa por hectare de povoamento de clones de eucalipto.

2. A fertilização pós-desbaste aos 99 meses não afeta a produção do povoamento.

3. O acúmulo de nutrientes na parte aérea e no tronco é inversamente proporcional à intensidade de desbaste e não é afetado significativamente pela fertilização pós-desbaste.
4. Na serapilheira, o desbaste afeta apenas a quantidade de cálcio, enquanto que a fertilização pós desbaste tem efeito sobre as quantidades de potássio, cálcio, magnésio e enxofre.

\section{Agradecimentos}

Ao Conselho Nacional de Desenvolvimento Científico e Tecnológico, por concessão de bolsa; à ArcelorMittal BioFlorestas, pelo apoio, concessão da área experimental, fornecimento de dados de inventário e disponibilização de estrutura para a realização das coletas.

\section{Referências}

ANDRADE, G. de C.; BELlOTE, A.F.J.; SILVA, H.D. da; RIZZI, N.E.; GAVA, J.L. Acúmulo de nutrientes na biomassa e na serapilheira de Eucalyptus grandis em função da aplicação de lixo urbano e de nutrientes minerais. Boletim de Pesquisa Florestal, n.53, p.109-136, 2006.

BARROS, N.F. de; NOVAIS, R.F. de; TEIXEIRA, J.J.; FERNANDES FILHO, E.I. Nutricalc 2.0 - sistema para cálculo del balance nutricional y recomendación de fertilizantes para el cultivo de eucalipto. Bosque, v.16, p.129-131, 1995.

BRANDANI, C.B. Decomposição de resíduos de eucalipto e efluxo de $\mathrm{C}-\mathrm{CO}_{2}$ em solos em diferentes locais do brasil. 2010. 72p. Dissertação (Mestrado) - Universidade Federal de Viçosa, Viçosa.

CAMPOS, J.C.C.; LEITE, H.G. Mensuração florestal: perguntas e respostas. 3.ed. Viçosa: UFV, 2009. 548p.

CAMPOS, J.C.C.; TURNBULL, K.J. Um sistema para estimar produção por classe de diâmetro e sua aplicação na interpretação do efeito de desbaste. Revista Árvore, v.5, p.1-16, 1981.

CHAVES, R.A.; REIS, M.G.F.; REIS, G.G.; PEZZOPANE, J.E.M.; XAVIER, A.; MONTE, M.A. Dinâmica de cobertura de dossel de povoamentos de clone de Eucalyptus grandis W. Hill ex-Maiden submetidos a desrama artificial e desbaste. Revista Árvore, v.31, p.989-998, 2007.

CUNHA, G. de M.; GAMA-RODRIGUES, A.C. da; COSTA, G.S. Ciclagem de nutrientes em Eucalyptus grandis W. Hill ex Maiden no Norte Fluminense. Revista Árvore, v.29, p.353-363, 2005.

DIAS, A.N. Um modelo para gerenciamento de plantações de eucalipto submetidas a desbaste. 2005. 135p. Tese (Doutorado) Universidade Federal de Viçosa, Viçosa.

FARIA, G.E. de; BARROS, N.F. de; CUNHA, V.L.P.; MARTINS, I.S.; MARTINS, R. de C.C. Avaliação da produtividade, conteúdo e eficiência de utilização de nutrientes em genótipos de Eucalyptus spp. no Vale do Jequitinhonha, MG. Ciência Florestal, v.18, p.363-373, 2008.

FREITAS, R.; SCHUMACHER, M.V.; CALDEIRA, M.V.W.; SPATHELF, P. Biomassa e conteúdo de nutrientes em povoamento 
de Eucalyptus grandis W. Hill ex Maiden plantado em solo sujeito à arenização, no Município de Alegrete-RS. Biomassa e Energia, v.1, p.93-104, 2004.

GAMA-RODRIGUES, A.C.; BARROS, N.F. Ciclagem de nutrientes em floresta natural e em plantios de eucalipto e de dandá no sudeste da Bahia, Brasil. Revista Árvore, v.26, p.193-207, 2002 .

GORGENS, E.B.; LEITE, H.G.; NOGUEIRA, G.S.; DIAS, A.N. Tendência de crescimento de povoamento de eucalipto após aplicação de desbaste. Revista Árvore, v.31, p.879-885, 2007.

HARRINGTON, C.A.; DEVINE, W.D. Stand development following precommercial thinning and fertilization treatments in a Western redcedar (Thuja plicata) dominated forest. Canadian Journal of Forest Research, v.41, p.151-164, 2011.

HAYWOOD, J.D. Influence of precommercial thinning and fertilization on total stem volume and lower stem form of loblolly pine. Southern Journal of Applied Forestry, v.29, p.215-220, 2005.

KANNINEN, M.; PEREZ, C.L.D.; MONTERO, M.; VIQUEZ, E. Intensity and timing of the first thinning of Tectona grandis plantations in Costa Rica: results of a thinning trial. Forest Ecology and Management, v.203, p.89-99, 2004.

KOLM, L.; POGGIANI, F. Ciclagem de nutrientes em povoamentos de Eucalyptus grandis submetidos à prática de desbastes progressivos. Scientia Forestalis, n.63, p.79-93, 2003.

LEITE, H.G.; NOGUEIRA, G.S.; DIAS, A.N. Desbastes e seus efeitos sobre a produção e a qualidade de povoamentos florestais. In: SEMINÁRIO SOBRE SILVICULTURA EM FLORESTAS PLANTADAS, 1., 2004, Vitória. Anais. Viçosa: UFV, 2004. p.165-195.

MEDHURST, L.; BEADLE, C.L.; NEILSEN, W.A. Early-age and later-age thinning affects growth, dominance, and intraspecific competition in Eucalyptus nitens plantations. Canadian Journal of Forest Research, v.31, p.187-197, 2001.

MILLER, H.G. The influence of stand development on nutrient demand, growth and allocation. Plant and Soil, v.168-169, p.225-232, 1995.

MONTE, M.A.; REIS, M. das G.F.; REIS, G.G.; LEITE, H.G.; CACAU, F.V.; ALVES, F. de F. Crescimento de um clone de eucalipto submetido a desrama e desbaste. Revista Árvore, v.33, p.777-787, 2009.
MÜLLER, M.D. Produção de madeira para geração de energia elétrica numa plantação clonal de eucalipto em Itamarandiba, MG. 2005. 108p. Tese (Doutorado) - Universidade Federal de Viçosa, Viçosa.

NOGUEIRA, G.S.; LEITE, H.G.; CAMPOS, J.C.C.; SOUZA, A.L. de; COUTO, L. Determinação da idade técnica de desbaste em plantações de eucalipto utilizando o método dos ingressos percentuais. Scientia Forestalis, n.59, p.51-59, 2001.

SANQUETTA,C.R.;REZENDE,A.V.; GAIAD,D.;SCHAAF,L.B.; ZAMPIER, A.C.; ARCE, J.E. Produção de madeira para celulose em povoamentos de Pinus taeda submetidos a diferentes densidades de plantio e regimes de desbaste: abordagem experimental. Cerne, v.10, p.154-166, 2004.

SANTANA, R.C.;BARROS, N.F. de;LEITE,H.G.; COMERFORD, N.B.; NOVAIS, R.F. de N. Estimativa de biomassa de plantios de eucalipto no Brasil. Revista Árvore, v.32, p.697-706, 2008.

SANTANA, R.C.; BARROS, N.F. de; NEVES, J.C.L. Eficiência de utilização de nutrientes e sustentabilidade da produção em procedências de Eucalyptus grandis e Eucalyptus saligna em sítios florestais do Estado de São Paulo. Revista Árvore, v.26, p.447-457, 2002.

SCHUMACHER, M.V.; POGGIANI, F. Produção de biomassa e remoção de nutrientes em povoamentos de Eucalyptus camaldulensis Dehnh, Eucalyptus grandis Hill ex Maiden e Eucalyptus torelliana $\mathrm{F}$. Muell, plantados em Anhembi, SP. Ciência Florestal, v.3, p.21-34, 1993.

SILVA, L.F. Necessidade de adubação pós-desbaste, baseada no balanço nutricional de povoamentos de eucalipto. 1999. 61p. Dissertação (Mestrado) - Universidade Federal de Viçosa, Viçosa.

STAPE, J.L.; BINKLEY, D.; JACOB, W.S.; TAKAHASHI, E.N. A twin-plot approach to determine nutrient limitation and potential productivity in Eucalyptus plantations at landscape scales in Brazil. Forest Ecology and Management, v.223, p.358-362, 2006.

TREVISAN, R.; HASELEIN, C.R.; SANTINI, E.J.; SCHNEIDER, P.R.; MENEZES, L.F. de. Efeito da intensidade de desbaste nas características dendrométricas e tecnológicas da madeira de Eucalyptus grandis. Ciência Florestal, v.17, p.377-387, 2007.

WOLLUM, A.G.; SCHUBERT, G.H. Effect of thinning on the foliage and forest floor properties of ponderosa pine stands. Soil Science Society of America Journal, v.39, p.968-972, 1975.

Recebido em 26 de abril de 2012 e aprovado em 19 de outubro de 2012

Pesq. agropec. bras., Brasília, v.47, n.11, p.1555-1562, nov. 2012 